\title{
Synthesis and Characterization of a Three Component Polyhydroxyalkanoates Containing Medium-Chain-Length Monomers of 3-Hydroxyhexanoate
}

\author{
Daria A. Syrvacheva*a and Natalia O. Zhila ${ }^{\mathrm{a}, \mathrm{b}}$ \\ ${ }^{a}$ Siberian Federal University \\ 79 Svobodny, Krasnoyarsk, 660041, Russia \\ ${ }^{b}$ Institute of Biophysics SB RAS \\ 50/50 Akademgorodok, Krasnoyarsk, 660036, Russia
}

Received 01.02.2016, received in revised form 30.03.2016, accepted 28.05.2016

The synthesis of poly(3-hydroxybutyrate/3-hydroxyvalerate/3-hydroxyhexanoate) [P(3HB/3HV/3HHx)] and poly(3-hydroxybutyrate/3-hydroxyhexanoate/diethylene glycol) [P(3HB/3HHx/DEG)] by Cupriavidus eutrophus B10646 was studied. Cultivation conditions of Cupriavidus eutrophus B10646 enabled production of high biomass yields and high content of the polymer. Three component copolymers $[P(3 H B / 3 H V / 3 H H x)$ and $P(3 H B / 3 H H x / D E G)]$ were synthesized with different content of $3 H H x$ monomers. The physical and chemical properties of copolymers, including the degree of crystallinity, molecular weight and temperature characteristics and surface properties of the film samples were studied.

Keywords: polyhydroxyalkanoates, biosynthesis, copolymers, 3-hydroxyvalerate, 3-hydroxyhexanoate, diethylene glycol, physical and chemical properties.

DOI: $10.17516 / 1997-1389-2016-9-2-153-161$.

(C) Siberian Federal University. All rights reserved

* Corresponding author E-mail address: syrvachevada@yandex.ru 


\title{
Синтез и характеристика 3-компонентных \\ полигидроксиалканоатов, содержащих мономеры среднецепочечного \\ 3-гидроксигексаноата
}

\author{
Д.А. Сырвачева ${ }^{a}$, Н.О. Жила \\ ${ }^{a}$ Сибирский федеральный университет \\ Россия, 660041, Красноярск, пр. Свободный, 79 \\ ${ }^{6}$ Институт биофизики СО РАН \\ Россия, 660036, Красноярск, Академгородок, 50/50
}

Исследованы режимы выращивания Cupriavidus eиtrophus B10646, обеспечивающие продуктивный синтез трехкомпонентных сополимеров ПГА, содержащих мономеры 3-гидроксигексаноата (ЗГГ), а также 3-гидроксибутирата (ЗГБ), 3-гидроксивалерата (ЗГВ) и диэтиленгликоля (ДЭГ) при сохранении общих выходов ПГА и урожая биомассы клеток на высоком уровне. Синтезированы 3-компонентные сополимеры [П(ЗГБ/ЗГВ/ЗГГ) и П(ЗГБ/ЗГГ/ДЭГ)] с различным содержанием мономеров ЗГГ и изучены их физико-химические свойства, включая степень кристалличности, молекулярно-массовые и температурные характеристики, а также свойства поверхности пленочных образиов.

Ключевые слова: полигидроксиалканоаты, биосинтез, сополимеры, 3-гидроксивалерат, 3-гидроксигексаноат, диэтиленгликоль, физико-химические свойства.

\section{Введение}

Полигидроксиалканоаты (ПГА) - это семейство полимеров различной химической структуры, различающихся базовыми физико-химическими свойствами. В зависимости от строения мономеров, входящих в состав ПГА, они разделяются на короткоцепочечные, среднецепочечные и длинноцепочечные, соответственно, состоящие из мономеров с длиной С-цепи $\mathrm{C}_{3}-\mathrm{C}_{5} ; \mathrm{C}_{6}-\mathrm{C}_{14}$; свыше $\mathrm{C}_{14}$ (Steinbüchel and Valentin, 1995). Особо перспективными ПГА являются сополимеры, имеющие низкую кристалличность и обладающие свойствами эластомеров. Это короткоцепочечные сополимеры 3- и 4-гидроксибутирата, а также сополимеры, содержащие, помимо короткоцепочечных, 2012). среднецепочечные мономеры 3-гидроксигексаноата (3ГГ) или 3-гидроксиоктаноата (ЗГО) (Madison and Huisman, 1999; Sudesh et al., 2000; Laycock et al., 2014). Однако синтез сополимерных ПГА является сложной биотехнологической задачей, так как для их получения в состав среды, как правило, необходимо внесение дополнительных источников углерода в качестве субстратовпредшественников целевых мономеров, которые в подавляющем большинстве ингибируют рост продуцентов. Это негативно сказывается на общей продуктивности процесса биосинтеза (как на приросте биомассы клеток, так и на выходах сополимеров) (Bhubalan et al., 2008, 2010; Cavalheiro et al., 
Возможности продуктивного синтеза ПГА, содержащих мономеры 3-гидроксигексаноата, дополнительно осложняются спецификой метаболизма гексаноата как субстрата-предшественника, так как он метаболизируется в цикле $\beta$-окисления жирных кислот на более короткие фрагменты $\left(\mathrm{C}_{4}+\right.$ $\mathrm{C}_{2}$ ), снижая тем самым количество субстрата для образования и включения в полимерную цепь мономеров ЗГГ. Поэтому получение высоких выходов ПГА с высоким содержанием среднецепочечных мономеров - труднореализуемая задача, для ее решения необходимо организовать условия, при которых блокируются реакции $\beta$-окисления гексаноата. Трудности регламентированного и воспроизводимого синтеза сополимерных ПГА сдерживают накопление знаний о влиянии состава мономеров на физико-химические свойства полимера.

Это определило направленность настоящей работы, ориентированной на изучение возможности продуктивного синтеза ПГА, содержащих мономеры среднецепочечного 3-гидроксигексаноата и выявление взаимосвязи между структурой сополимеров этого типа и их свойствами.

\section{Материалы и методы}

Исследована культура бактерий Cupriavidus eutrophus B10646, характеризующаяся способностью синтезировать ПГА на различных углеродных субстратах. Для выращивания бактерий за основу принята минеральная среда Шлегеля (Schlegel et al., 1961). Бактерии выращивали в периодической автотрофной и гетеротрофной культурах в режиме синтеза ПГА с лимитированным содержанием азота в среде (40 \% от потребности культуры в элементе). Длительность культивирования составляла 48-72 ч. Проведено четыре серии экспериментов. В первой серии эксперимен- тов бактерии выращивали в периодической автотрофной $\left(\mathrm{CO}_{2}+\mathrm{H}_{2}+\mathrm{O}_{2}\right)$ культуре. Для синтеза многокомпонентных ПГА, содержащих мономеры 3-гидроксивалерата (3ГВ) и 3-гидроксигексаноата (3ГГ), в состав среды в качестве субстратов-предшественников вносили валерат натрия $(0,5$ г/л) и гексаноат натрия («Acros Organics», США). С учетом возможного усиления токсичности при сочетанной подаче в культуру валерата натрия и гексаноата натрия последний вносили дробно в течение всего эксперимента через каждые 6-8 ч (концентрация разовой дозы в различных экспериментах варьировала от 0,5 до 0,7 г/л). Общее количество добавок гексаноата натрия в разных экспериментах составляло от одной до трех. Далее во второй, третьей и четвертой сериях экспериментов бактерии выращивали в периодической гетеротрофной культуре. В качестве основного ростового субстрата использовали глюкозу в концентрации 10 г/л. Для блокирования реакций цикла $\beta$-окисления жирных кислот и усиления синтеза мономеров ЗГГ в культуру при выращивании бактерий на гетеротрофных субстратах одновременно с гексаноатом натрия вносили акрилат натрия («Sigma», CША). Подачу гексаноата натрия и акрилата натрия в культуру делали через каждые 6-8 ч в течение эксперимента в концентрациях 0,5 и 0,05 г/л соответственно. Во второй серии экспериментов в качестве субстратов-предшественников для синтеза мономеров ЗГВ использовали валерат натрия, а в третьей - пропионат натрия в различных концентрациях $(0,5 ; 0,7 ; 1,0$ г/л), которые вносили в культуру однократно на 38-42 ч культивирования бактерий. В четвертой серии экспериментов исследована возможность получения 3-компонентных сополимерных ПГА, в которых, помимо мономеров ЗГБ и ЗГГ, присутствуют мономеры диэтиленгликоля (ДЭГ). Диэтиленгликоль 
(ОАО «Нижнекамскнефтехим», Россия) подавали однократно в концентрации 30 г/л в культуру различного возраста $(1,24,48$ ч культивирования).

Накопление биомассы в культуре $(\mathrm{X}$, г/л) определяли измерением оптической плотности и по весу абсолютно сухого вещества. Внутриклеточное содержание и состав ПГА определяли на хромато-массспектрометре Agilent Technologies 7890A c масс-детектором Agilent Technologies 5975C (Agilent, США). Для определения мономеров диэтиленгликоля сняты ${ }^{1} \mathrm{H}-Я М Р$ спектры растворов полимеров в дейтерированном хлороформе $\left(\mathrm{CDCl}_{3}\right)$ с использованием ЯМР-спектрометра Advance III 600 (Bruker, Германия).

Физико-химические свойства полученных ПГА исследовали с применением рентгеноструктурного анализа D8 Advance («Bruker», Германия), дифференциального термического анализа DSC-1 (Mettler Toledo, Швейцария) и высокоэффективной жидкостной хроматографии Agilent Technologies 1260 Infinity (Agilent, Германия). Для анализа структуры поверхности были изготовлены плотные гладкие пленки из 1,5\% растворов ПГА в хлороформе методом полива растворов полимеров с последующим испарением растворителя. Микроструктуру поверхности пленочных образцов исследовали с помощью сканирующей электронной микроскопии S5500 (Hitachi, Япония), свойства поверхности - на приборе для измерения краевых углов смачивания поверхности DSA-25E (Krüss, Германия).

Статистическую обработку результатов проводили общепринятыми методами с использованием стандартного пакета программ Microsoft Excel. Результаты представлены как средние арифметические со стандартным отклонением.

\section{Результаты и обсуждение}

Результаты исследования возможности синтеза трехкомпонент-


C. eutrophus B10646 в автотрофных условиях при подаче в культуру двух субстратовпредшественников - валерата натрия и гексаноата натрия - представлены на рис. 1а. С увеличением концентрации гексаноата натрия в культуре содержание мономеров ЗГГ в П(ЗГБ/ЗГВ/ЗГГ) увеличивалось. Максимальное включение 3ГГ (17-25 мол.\%) зарегистрировано при подаче в культуру 3 добавок гексаноата натрия (суммарно до 2,0-2,1 г/л). При этом общий выход сополимера составлял 45 \% от веса сухой биомассы, а урожай биомассы находился на уровне 2,3-2,5 г/л. Содержание мономеров ЗГВ в П(ЗГБ/ЗГВ/3ГГ) в разных опытах варьировало от 21 до 30 мол.\%.

Для повышения продукционных характеристик культуры C. eutrophus B10646 автотрофный углеродный субстрат был заменен гетеротрофным (глюкоза). Во второй и третьей серии экспериментов общий выход сополимера и содержание в нем мономеров


субстратов-предшественников (рис. 1б, в). Однако выход сополимера в экспериментах с валератом натрия достигал 38-44 \% от веса сухой биомассы при суммарном содержании мономеров ЗГВ и ЗГГ на достаточно высоком уровне (43-48 мол.\%). Доля мономеров ЗГВ варьировала от 33 до 41 мол.\%, доля мономеров ЗГГ была ниже (7-15 мол.\%) (рис. 1б).

При замене валерата натрия пропионатом натрия (рис. 1в) общий выход П(ЗГБ/3ГВ/ЗГГ) увеличился до 45-52 \% от веса сухой биомассы, при этом суммарное содержание мономеров ЗГВ и ЗГГ было несколько ниже (на уровне 27-31 мол.\%). Доля мономеров ЗГГ в сополимере составляла от 12 до 16 мол.\%; 


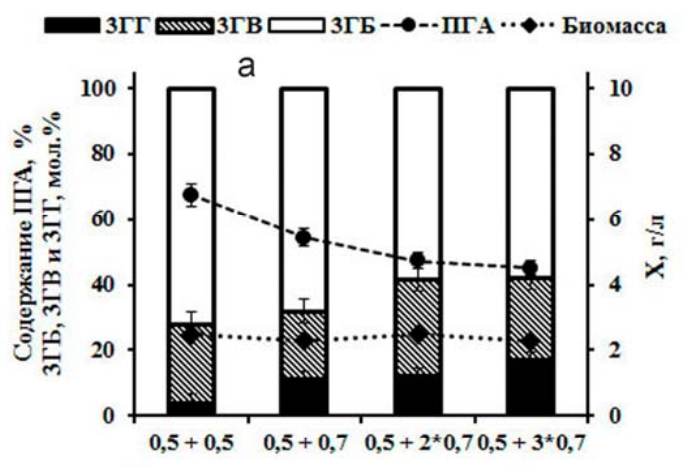

Концентрация предшественника (валерат натрия + гексаноат натрия), $\mathrm{r} / \mathrm{s}$

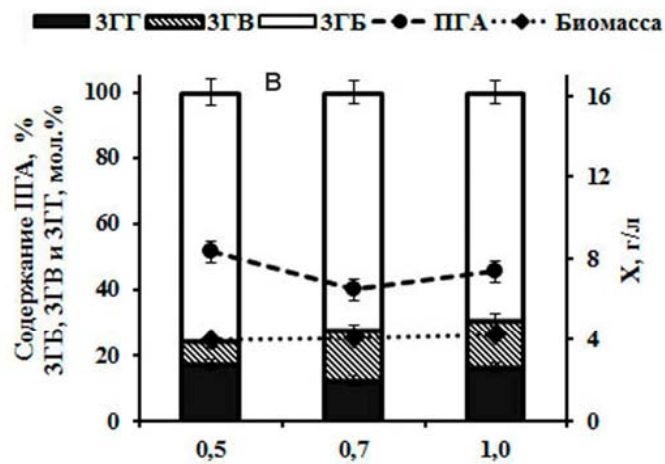

Концентрация пропионата натрия, г/л



б

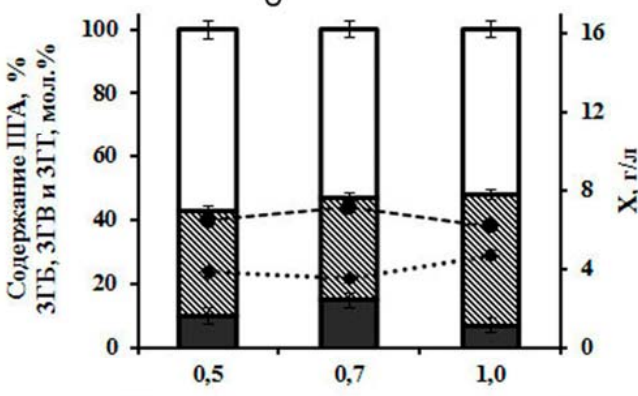

Концентрация валерата натрия, г/л


Рис. 1. Рост культуры Cupriavidus eutrophus В10646 и синтез 3-компонентных сополимеров П(ЗГБ/3ГВ/ ЗГГ) в автотрофных условиях (1a), П(3ГБ/ЗГВ/3ГГ) $(16,1$ в) и П(3ГБ/ЗГГ/ДЭГ) (1г) в гетеротрофных условиях при различном режиме дозирования гексаноата натрия, акрилата натрия, валерата натрия или пропионата натрия, диэтиленгликоля. $1 \mathrm{a}-2^{*}$ и $3^{*}-$ количество добавок гексаноата натрия при концентрации валерата натрия 0,5 г/л; 16 и 1в - разовая добавка гексаноата натрия и акрилата натрия составляла 0,5 и 0,05 г/л соответственно при концентрациях валерата натрия или пропионата натрия 0,$5 ; 0,7 ; 1,0$ г/л; 1г - однократная подача ДЭГ (30 г/л) на 1, 24 или 48 ч культивирования и дробной подаче гексаноата натрия и акрилата натрия в культуру (разовая доза 0,5 г/л и 0,05 г/л соответственно)

мономеров 3ГВ - 14-15 мол.\%. Максимальное содержание сополимера в клетках бактерий (52\% от веса сухой биомассы) получено при минимальной концентрации пропионата натрия в культуре $(0,5$ г/л). Урожай биомассы во всех экспериментах находился в границах $4,0-4,5$ г/л.

Исследована возможность получения 3-компонентных сополимерных ПГА нового типа, в которых, помимо мономеров ЗГБ и ЗГГ, присутствуют мономеры диэтиленгликоля (ДЭГ). Эти сополимеры относят к «необычным» ПГА. Известно, что при наличии в культивационной среде полиэтиленгликоля (ПЭГ) возможен микробиологический синтез диблок-сополимера ПГА/ПЭГ, где карбоксильный конец (-СООН) цепей ПГА ковалентно связан эфирной связью с цепью ПЭГ. Это явление было названо PEGylation (Foster, 2007). Для синтеза 3-компонентных П(ЗГБ/ЗГГ/ ДЭГ) культивирование бактерий C. eutrophus В10646 проводили в гетеротрофных условиях с использованием раствора глюкозы, где в качестве субстрата-предшественника для синтеза мономеров этиленгликоля (ЭГ) использовали диэтиленгликоль (ДЭГ) наряду с 
добавками гексаноата натрия и акрилата натрия (рис. 1г).

Урожай биомассы клеток в опытах имел близкие значения $(2,5-2,7$ г/л). Однако выход сополимера и содержание в нем мономеров ЗГГ и ДЭГ варьировали. Наибольшее включение мономеров этиленгликоля (0,5 и 0,7 мол.\%) зафиксировано при подаче ДЭГ в раннюю культуру (1 и 24 ч соответственно). При этом доля ЗГГ мономеров составляла 0,3 мол.\%. При более поздней подаче ДЭГ в культуру (48 ч) содержание ЭГ было ниже $(0,15$ мол.\%), в то время как содержание мономеров ЗГГ увеличилось до 3,0 мол.\%. Общий выход сополимера находился в диапазоне от 40 до 61 \% от веса сухой биомассы в зависимости от времени добавления ДЭГ в культуру.

Таким образом, варьируя подаваемые в среду субстраты-предшественники, их концентрацию в культуре, а также условия углеродного питания, синтезирована уникальная линейка трехкомпонентных ПГА с содержанием 3ГВ от 14 до 41 мол.\%, ЗГГ от 2 до 16 мол.\% и ДЭГ от 0,15 до 0,7 мол.\% (таблица).

При изучении молекулярно-массовых характеристик 3-компонентных сополимеров показано, что для них характерно снижение значений средневесовой молекулярной массы и возрастание полидисперсности по сравнению с гомополимером П(ЗГБ) (табл.). Особенно это было выражено у образцов П(ЗГБ/ЗГГ/ДЭГ), для которых зарегистрированы самые высокие значения полидисперсности (ПД) (до 7,02 и 15,42). У одного образца П(ЗГБ/ЗГГ/ДЭГ) обнаружена гетерогенность фракций с различными значениями $\mathrm{M}_{\mathrm{B}}$ : низкомолекулярного (14 кДа) и высокомолекулярного (731 кДа). Также во всех синтезированных 3-компонентных образцах

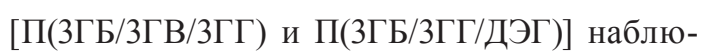

дались изменения термического поведения и появление двух пиков в области плавления. Первый пик плавления зафиксирован в области 148-156 ${ }^{\circ} \mathrm{C}$; второй - 162-171 ${ }^{\circ} \mathrm{C}$. Температура термической деградации образцов П(3ГБ/ЗГГ/ДЭГ) и образцов П(ЗГБ/ЗГВ/ЗГГ) с различным содержанием мономеров 3ГВ, ЗГГ и ДЭГ практически не изменялась относительно П(ЗГБ) $\left(290^{\circ} \mathrm{C}\right)$ и находилась в диапазоне от 288 до $297{ }^{\circ} \mathrm{C}$. Степень кристалличности сополимеров с диэтиленгликолем (68-75 \%) имела незначительные различия с гомополимером (76 \%), в то время как у П(3ГБ/ЗГВ/3ГГ) эти показатели были ниже и составляли 43-61 \% (табл.).

Для исследования биологических свойств 3-компонентных ПГА были получены плотные гладкие пленки. РЭМ-снимки пленок представлены на рис. 2. По результатам РЭМ морфология поверхности сополимерных пленок значительно отличается от поверхности пленок из гомополимера П(ЗГБ), имеющих более гладкую плотнозернистую поверхность с малым количеством мелких пор. Пленки сополимерных образцов имеют более выраженный рельеф, отличающийся наличием множества пор (от 1 до 23 на см²) различного диаметра (от 5 до 75 мкм).

Анализ свойств поверхности пленок из ПГА различного химического состава включал измерение краевых углов смачивания водой и дийодметаном с последующим вычислением свободной поверхностной энергии, ее дисперсной и полярной составляющих (табл.). Результаты показали отличия в величине краевых углов смачивания водой; у пленок, изготовленных из П(ЗГБ/ЗГВ/ЗГГ), угол составлял $74,8-88,2^{\circ}$, у гомополимера П(ЗГБ) - 92, $8^{\circ}$. Значения свободной энергии межфазной поверхности исследуемых полимеров были близки -

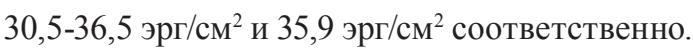




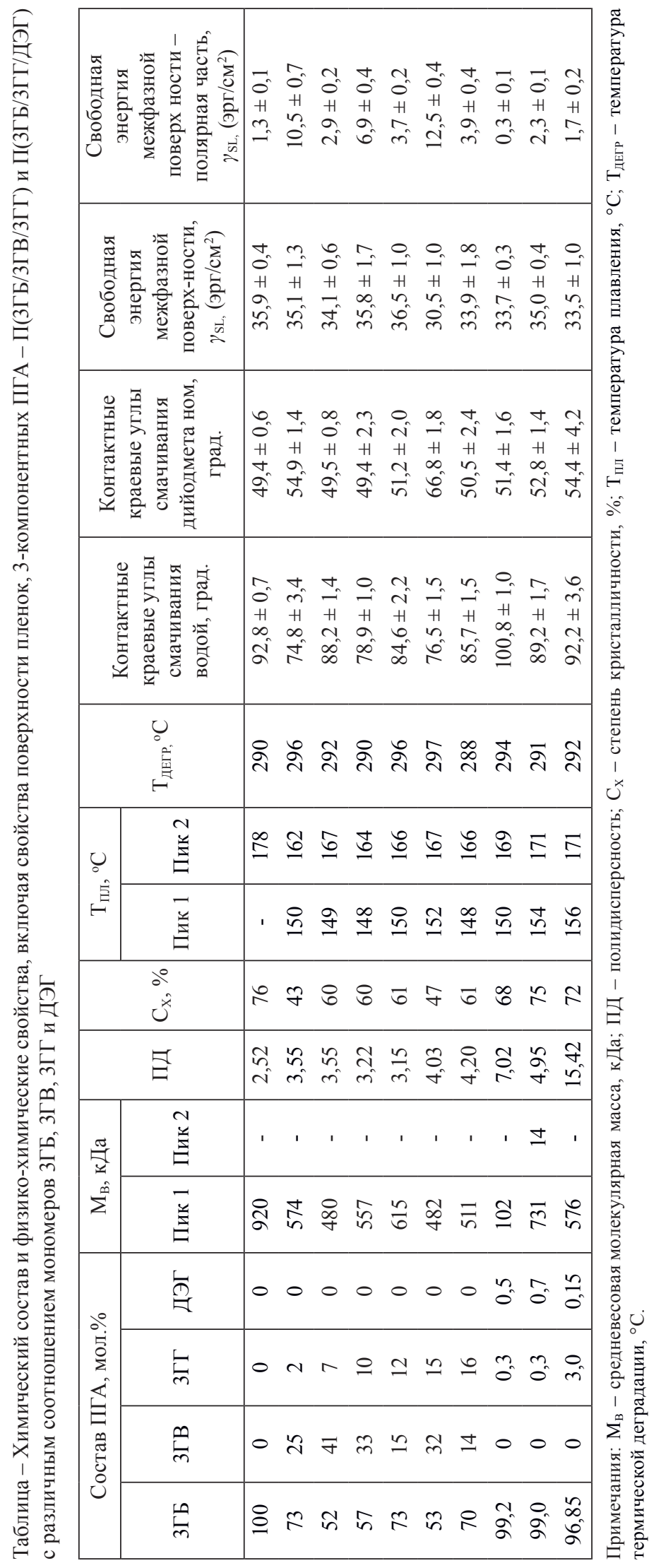




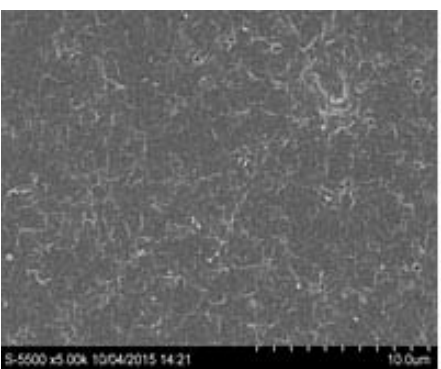

П(3ГБ)

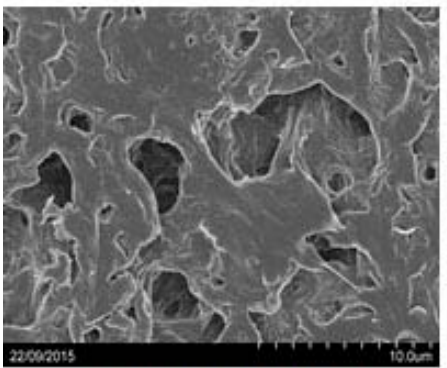

П(3ГБ/3ГГ/ДЭГ $)$

$(98,85 / 3,0 / 0,15)$

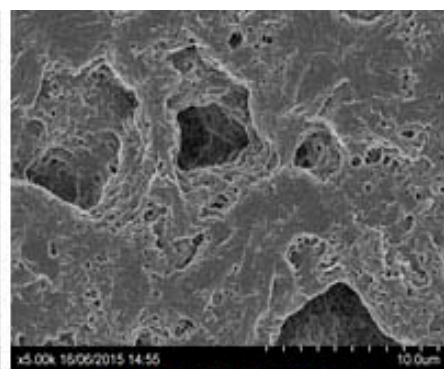

П $(3 \Gamma Б / 3 \Gamma \mathrm{B} / 3 \Gamma \Gamma)$ $(53,0 / 32,0 / 15,0)$

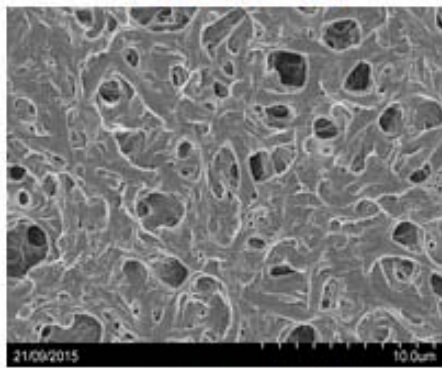

П(3ГБ/3ГГ/ДЭГ)

$(99,2 / 0,3 / 0,5)$

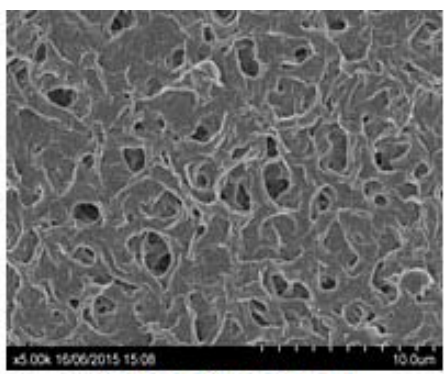

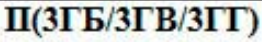

$(69,5 / 14,5 / 16,0)$

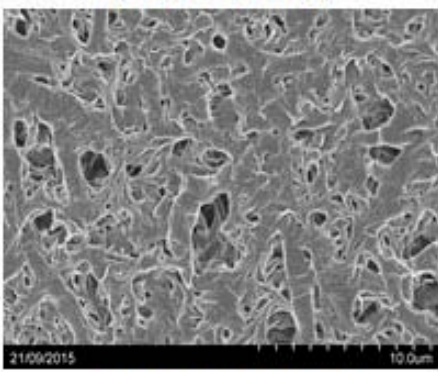

П(ЗГБ/ЗГГ/ДЭГ)

$(99,0 / 0,3 / 0,7)$

Рис. 2. РЭМ-снимки пленок, полученных из П(ЗГБ), П(ЗГБ/3ГВ/ЗГГ), П(ЗГБ/ЗГГ/ДЭГ) с различным содержанием (мол.\%) мономеров ЗГБ, ЗГВ, ЗГГ и ДЭГ (маркер 100 мкм)

Показано увеличение полярной энергии (2,9-

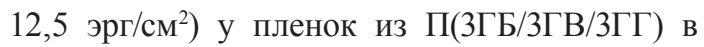
сравнении с таковой у П(ЗГБ) $(1,30$ эрг/см²), что косвенно характеризует поверхность данных образцов как более гидрофильную. Полимерные пленки, содержащие в составе мономеры этиленгликоля (ЭГ), по измеряемым показателям близки к гомополимеру П(ЗГБ) - краевой угол смачивания водой $-89,2-100,8^{\circ}$, свободная энергия межфазной поверхности - 33,535,0 эрг $/ \mathrm{cm}^{2}$, величина полярной энергии - 0,32,3 эрг $/ \mathrm{cm}^{2}$.

\section{Заключение}

Реализована возможность синтеза 3-компонентных сополимерных ПГА, содержащих в своем составе мономеры 3-гидроксигексаноата (ЗГГ), а также мономеры ЗГБ, ЗГВ и ДЭГ. Синтезировано семейство 3-компонентных сополимеров
[П(ЗГБ/3ГВ/ЗГГ) и П(ЗГБ/ЗГГ/ДЭГ)] с различным набором и соотношением мономеров и исследованы их физико-химические свойства. Показана вариабельность молекулярномассовых характеристик без четкой связи с составом сополимеров и сохранение термостабильности. Зафиксирована гетерогенность по величине молекулярной массы у П(ЗГБ/ЗГГ/ДЭГ) и изменения в термическом поведении отдельных сополимерных ПГА. При анализе свойств поверхности пленок из ПГА показано увеличение величины полярной энергии у пленок из П(ЗГБ/ЗГВ/ЗГГ) в сравнении с таковой у П(ЗГБ), что косвенно характеризует поверхность данных образцов как более гидрофильную, в то время как полимерные пленки, содержащие в составе мономеры этиленгликоля (ЭГ), по измеряемым показателям близки к значениям гомополимера П(ЗГБ). 
Работа выполнена за счет средств государственного задания на проведение фундаментальных исследований РАН (проект № гос. регистрации 01201351505).

\section{Список литературы}

Bhubalan K., Lee W.H., Loo C.Y., Yamamoto T., Tsuge T., Doi Y., Sudesh K. (2008) Controlled biosynthesis and characterization of poly(3-hydroxybutyrateco-3-hydroxyvalerate-co-3hydroxyhexanoate) from mixtures of palm kernel oil and 3HV-precursors. Polym. Degrad. Stabil., 93: $17-23$

Bhubalan K., Rathi D.N., Abe H., Iwata T., Sudesh K. (2010) Improved synthesis of P(3HBco-3HV-co-3HHx) terpolymers by mutant Cupriavidus necator using the PHA synthase gene of Chromobacterium sp. USM2 with high affinity towards 3HV. Polym. Degrad. Stabil., 95: 1436-1442

Cavalheiro J.M.B.T., Raposo R.S., de Almeida M.C.M.D., Cesário M.T., Sevrin C., Grandfils C., da Fonseca M.M.R. (2012) Effect of cultivation parameters on the production of poly(3-hydroxybutyrateco-4-hydroxybutyrate) and poly(3-hydroxybutyrate-4-hydroxybutyrate-3-hydroxyvalerate) by Cupriavidus necator using waste glycerol. Biores. Technol., 111: 391-397

Foster L.J.R. (2007) Biosynthesis, properties and potential of natural-synthetic hybrids of polyhydroxyalkanoates and polyethylene glycols. Appl. Microbiol. Biotechnol., 75: 1241-1247

Laycock B., Arcos-Hernandez M.V., Langford A., Buchanan J., Halley P.J., Werker A., Lant P.A., Pratt S. (2014) Thermal properties and crystallization behavior of fractionated blocky and random polyhydroxyalkanoate copolymers from mixed microbial cultures. J. Appl. Polym. Sci., 131: 4083640854

Madison L.L., Huisman G.W. (1999) Metabolic engineering of poly(3-hydroxyalkanoates): from DNA to plastic. Microbiol. Mol. Biol. Rev., 63: 21-53

Schlegel H.G., Kaltwasser H., Gottschalk G. (1961) A submersion method for culture of hydrogenoxidizing bacteria: growth physiological studies. Arch. Microbiol., 38: 209-222

Steinbüchel A., Valentin H.E. (1995) Diversity of bacterial polyhydroxyalkanoiv acids. FEMS Microbiol. Lett., 128: 219-228

Sudesh K., Abe H., Doi Y. (2000) Synthesis, structure and properties of polyhydroxyalkanoates: biological polyesters. Prog. Polym. Sci., 25: 1503-1555 